Virtual Mentor. January 2005, Volume 7, Number 1.

doi: 10.1001/virtualmentor.2005.7.1.ccas2-0501

Module 1

\title{
Case 1.2: Fundamentals of the Patient-Physician Relationship-Mr. Jones Keeps Calling
}

\section{Case Presentation}

Dr. Stevens opts to accept Mr. Jones as his patient, meeting him for the first time in the emergency room. During the first appointment after his hospitalization, Mr. Jones expresses shock about the emergency and is concerned that his medical condition is deteriorating. He tells Dr. Stevens that he hopes he will never need to give himself insulin shots. Dr. Stevens talks with Mr. Jones about his concerns, reiterating the need for him to watch his diet, exercise, and, now, take his oral medication correctly and regularly.

Mr. Jones leaves the office feeling like he has less to worry about. However, every time he mentions going to the emergency room, people tell him about their diabetes and relate horror stories about relatives or acquaintances who have had limbs amputated or gone blind. Mr. Jones again becomes concerned and anxious about his condition. He calls Dr. Stevens' office several times during the next month asking to talk with the nurse or, preferably, Dr. Stevens.

As Dr. Stevens' practice grows he has less time to consult with patients over the telephone, especially with the same patient asking the same questions over and over. In addition, Dr. Stevens gets the sense that Mr. Jones is not doing all that he should to monitor and manage his illness. Mr. Jones's anxiety keeps rising, and Dr. Stevens becomes frustrated.

\section{What should Dr. Stevens do about Mr. Jones? (select an option)}
A. Tell Mr. Jones to schedule an appointment within the next two weeks and ask him to make a written list of his questions.
B. Tell Mr. Jones to "Come and see me when you're sticking to your diet and doing what I told you to do."
C. Tell the office assistant to explain to Mr. Jones that they will discuss his concerns during their next scheduled meeting time in three months.
D. Tell Mr. Jones that it would be helpful for him to see a diabetes educator at the hospital who could talk with him about appropriate diet and exercise.

The people and events in this case are fictional. Resemblance to real events or to names of people, living or dead, is entirely coincidental. The viewpoints expressed on this site are those of the authors and do not necessarily reflect the views and policies of the AMA.

(C) 2005 American Medical Association. All Rights Reserved. 
Virtual Mentor. January 2005, Volume 7, Number 1.

doi: 10.1001/virtualmentor.2005.7.1.ccas2a-0501

Module 1

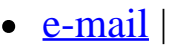

\section{Case 1.2: Fundamentals of the Patient-Physician Relationship-Mr. Jones Keeps Calling}

\section{Option Assessment}

A. Scheduling a follow-up appointment within two weeks to answer the patient's questions is the preferable option and is supported by Opinion 10.01 "Fundamental Elements of the Patient-Physician Relationship" that describes the relationship as a "collaborative" one in which the physician provides "information and guidance... with courtesy, respect, responsiveness and timely attention....

B. Dr. Stevens should avoid making adherence to treatment a condition for Mr. Jones's access to his physician. Opinion 10.01, "Fundamental Elements of the Patient-Physician Relationship" (2) states that the patient "has the right to make decisions regarding the health care that is recommended by his or her physician." To refuse Mr. Jones access implies that his right to health care depends on his adherence to Dr. Stevens' advice.

C. Asking Mr. Jones to wait three months to address his concerns should be avoided. Mr. Jones's telephone calls fall within the accepted behavior of one who is in the role of patient, eg, bringing medical concerns to the doctor who assesses the concerns, provides information to the patient and, if necessary, determines a medically appropriate treatment plan in collaboration with the patient. Opinion 10.01, "Fundamentals of the Patient-Physician Relationship," (1) speaks to the patient's right "to receive information... and guidance....as to the optimal course of action." In addition, failing to respond ignores the patient's "right to courtesy, respect, dignity, responsiveness, and timely attention to his or her needs."

D. Referring Mr. Jones to a diabetes educator is acceptable under Opinions 3.03, "Allied Health Professionals" and 3.04, "Referral of Patients," which affirm that physicians often work "in concert with allied health professionals." The principles that govern this collaboration assert that the referral must be made for the good of the patient and must be to an allied professional with appropriate training and licensing for his or her specific practice. The primary care physician has the obligation to cooperate with other providers in order to maintain the patient's "right to continuity of health care."

\section{Compare these options}

The people and events in this case are fictional. Resemblance to real events or to names of people, living or dead, is entirely coincidental. The viewpoints expressed on this site are those of the authors and do not necessarily reflect the views and policies of the AMA.

(C) 2005 American Medical Association. All Rights Reserved. 
Virtual Mentor. January 2005, Volume 7, Number 1.

doi: 10.1001/virtualmentor.2005.7.1.ccas2b-0501

Module 1

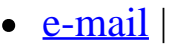

\section{Case 1.2: Fundamentals of the Patient-Physician Relationship-Mr. Jones Keeps Calling}

\section{Option Comparison}

Option A is preferable because scheduling a follow-up appointment within two weeks demonstrates compassion for the patient's suffering and acknowledges the patient's right to bring concerns and questions to the physician. Option B — refusing to see the patient until he demonstrates compliance with the treatment plan—should be avoided because it fails to respect Mr. Jones's freedom to make decisions, and it may undermine the collaborative relationship. Option C — asking the patient to wait three months to address his concerns - should be avoided also, because it fails to provide a timely response to the patient's legitimate concerns. Option D-referring the patient to an allied health professionalis acceptable and is very often an adjunct element of the treatment plan.

Preferable: Option A

Acceptable: Option D

Avoid: Options B and C

$\underline{\text { Additional discussion and information }}$

The people and events in this case are fictional. Resemblance to real events or to names of people, living or dead, is entirely coincidental. The viewpoints expressed on this site are those of the authors and do not necessarily reflect the views and policies of the AMA.

(C) 2005 American Medical Association. All Rights Reserved. 
Virtual Mentor. January 2005, Volume 7, Number 1.

doi: 10.1001/virtualmentor.2005.7.1.ccas2c-0501

Module 1

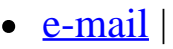

\section{Case 1.2: Fundamentals of the Patient-Physician Relationship-Mr. Jones Keeps Calling}

\section{Additional Information}

Collaboration, the hallmark of contemporary patient-physician interactions, is only possible in a trusting relationship. Patients need to trust that their well-being will be the primary consideration, and physicians need to trust patients to provide accurate information and appropriate feedback. New patients, particularly those first seen during emergencies, may not immediately trust their physicians, and, even when patients and physicians have worked together over time, a new medical event may alter the nature of the relationship. Physicians can sometimes view repetitive phone calls from their patients - especially those who seem to ignore the medical advice they receive-as impositions on their time. But these telephone calls are signs that the patient considers him- or herself to be in a relationship with a physician and that he or she trusts the physician.

Providing follow-up appointments allows the physician to assess the patient's on-going medical status and provides an opportunity to clarify the patient's understanding of what has been said to him or her during previous appointments. Moreover, such discussions engage the patient in the shared responsibility for maintaining or restoring his or her health. The physician's demonstrated commitment to patient care fosters or improves the patient-physician relationship.

\section{$\underline{\text { Next Case }}$}

\section{Module 1 Table of Contents}

The people and events in this case are fictional. Resemblance to real events or to names of people, living or dead, is entirely coincidental. The viewpoints expressed on this site are those of the authors and do not necessarily reflect the views and policies of the AMA.

(C) 2005 American Medical Association. All Rights Reserved. 